Fixed Point Theory, 18(2017), No. 1, 385-390

http://www.math.ubbcluj.ro/ nodeacj/sfptcj.html

\title{
A NEGATIVE ANSWER TO POPESCU'S CONJECTURE
}

\author{
TOMONARI SUZUKI
}

Department of Basic Sciences, Kyushu Institute of Technology

Tobata, Kitakyushu 804-8550, Japan

Department of Mathematics, Faculty of Science, King Abdulaziz University

Jeddah, Saudi Arabia

E-mail: suzuki-t@mns.kyutech.ac.jp

Abstract. We give a negative answer to Popescu's conjecture on some fixed point theorem in complete metric spaces, which was raised in 2013.

Key Words and Phrases: Fixed point, complete metric space.

2010 Mathematics Subject Classification: 47H10, 54H25.

\section{REFERENCES}

[1] S. Banach, Sur les opérations dans les ensembles abstraits et leur application aux équations intégrales, Fund. Math., 3(1922), 133-181.

[2] M. Kikkawa, T. Suzuki, Three fixed point theorems for generalized contractions with constants in complete metric spaces, Nonlinear Anal., 69(2008), 2942-2949.

[3] O. Popescu, A new type of contractive multivalued operators, Bull. Sci. Math., 137(2013), 30-44.

[4] T. Suzuki, A generalized Banach contraction principle that characterizes metric completeness, Proc. Amer. Math. Soc., 136(2008), 1861-1869.

[5] T. Suzuki and M. Kikkawa, Some remarks on a recent generalization of the Banach contraction principle, in Proceedings of the Eighth International Conference on Fixed Point Theory and its Applications (S. Dhompongsa, K. Goebel, W. A. Kirk, S. Plubtieng, B. Sims, and S. Suantai Eds.), Yokohama Publishers, 2008, 151-161

Received: January 23, 2014; Accepted: December 4, 2014.

The author is supported in part by Grant-in-Aid for Scientific Research from Japan Society for the Promotion of Science. 
